\title{
Ultra-thin Laminated Metal Composites with Ultra-high Strength and Excellent Soft Magnetic Properties
}

\author{
Le Zhang $^{1,2} \cdot$ Wei Wang $^{1,3} \cdot$ Xiaofei Xiao $^{1,2} \cdot$ M. Babar Shahzad ${ }^{1} \cdot$ Yiyin Shan $^{1,3} \cdot$ Ke Yang $^{1}$
}

Received: 13 June 2019 / Revised: 19 August 2019 / Published online: 15 October 2019

(C) The Chinese Society for Metals (CSM) and Springer-Verlag GmbH Germany, part of Springer Nature 2019

\begin{abstract}
Structural metallic materials with excellent functional performance and lightweight features have always been the goal of material scientists' pursuit. In this work, laminated metal composites of different thicknesses (less than $0.4 \mathrm{~mm}$ ) composed of structural materials with great differences in deformation ability were successfully fabricated via a novel processing procedure. Ultra-high strength and excellent soft magnetic properties were combined perfectly in the ultra-thin and super-light laminated metal composite strips due to unique structural design and essential attributes of the initial materials. These results emphasize the significant potential application value of the ultra-thin laminated metal composites in the field of structural and functional integration.
\end{abstract}

Keywords Laminated metal composites $\cdot$ Ultra-high strength $\cdot$ Ultra-thin $\cdot$ Soft magnetic property $\cdot$ Maraging steel

\section{Introduction}

The design principle of hierarchical structures inspired by natural materials, such as nacre, which possess not only high strength but also excellent fracture toughness due to their unique laminated structure alternated with both hard and soft phases [1-3], has been widely utilized in the synthesis and fabrication of novel functional or engineering materials [4-6]. Moreover, the lightweight of structural components has always been a key area of concern [7, 8]. The appearance of multilayer composites, especially laminated metal composites (LMCs), provides a new possibility to combine great loading capacity with excellent functional performance

Available online at http://link.springer.com/journal/40195

Wei Wang

wangw@imr.ac.cn

Ke Yang

kyang@imr.ac.cn

1 Institute of Metal Research, Chinese Academy of Sciences, Shenyang 110016, China

2 School of Materials Science and Engineering, University of Science and Technology of China, Hefei 230026, China

3 Key Laboratory of Nuclear Materials and Safety Assessment, Institute of Metal Research, Chinese Academy of Sciences, Shenyang 110016, China as well as the lightweight requirements for materials or some structural components. Bouaziz et al. [4] fabricated a bilayered composite composed of high-manganese twinninginduced plasticity (TWIP) steel and martensitic steel by hot rolling. Such bilayered steel possesses the advantages of both the TWIP steel (high ductility) and martensitic steel (high yield stress). $\mathrm{Al} / \mathrm{Ni}$ and $\mathrm{Al} / \mathrm{Ni} / \mathrm{Fe}_{3} \mathrm{O}_{4}$ multilayered composites were fabricated via accumulative rolling bonding reported by Daneshvar et al. [6]. The $\mathrm{Al} / \mathrm{Ni}(0.5)$ composite exhibited the highest tensile strength of about $182 \mathrm{MPa}$ and the highest saturation magnetization of $13.47 \mathrm{emu} / \mathrm{g}$.

At present, hot pressing [9], hot rolling [4], cold rolling [10], explosion welding [11] and accumulative rolling bonding [6], as the mainstream of fabrication methods, have been extensively applied for exploiting novel LMCs. The principle of the fabrication process is that the atoms between heterogeneous interfaces are activated by large deformation and/or thermal diffusion, which eventually forms a firm metallurgical bonding [5]. In addition to interface bonding, deformation coordination between heterogeneous materials which could have a huge impact on overall performance is another key point that needs to be seriously considered [5]. So far, multilayer metal composites consisting of original materials with great ductility and similar deformation capabilities have been effectively prepared and applied in the engineering structure, for example, $\mathrm{Al} / \mathrm{Al}$ [12], $\mathrm{Al} / \mathrm{Cu}$ [13], $\mathrm{Al} / \mathrm{Ni}$ [14], $\mathrm{Al} /$ 
Ti [15], $\mathrm{Cu} / \mathrm{Nb}$ [16], $\mathrm{Al} / \mathrm{Mg}$ [17], $\mathrm{Cu} / \mathrm{steel}$ [18] and so on. But it has been a great challenge to prepare laminated metal composites with a great difference in mechanical properties or with poor deformation ability.

In this work, a new method was developed to prepare a novel multilayer metal composite consisting of ultrahigh-strength maraging steel and ductile $316 \mathrm{~L}$ austenite stainless steel. Except for conventional thickness of the multilayer metal composite, ultra-thin multilayer composite strips with a thickness of 400-40 $\mu \mathrm{m}$ were successfully prepared. Apart from the large difference in deformation ability, the magnetic properties of these two initial materials were also quite different. Generally, maraging steels are regarded as ferromagnetic [19], while $316 \mathrm{~L}$ is non-magnetic or weak magnetic [20]. When 316L was deformed severely, due to the strain-induced martensite phase transformation, not only the strength increased, but it also showed a certain degree of magnetism [20]. So, a trial was made to fabricate ultra-thin novel LMCs composed of two materials mentioned above which combined the mechanical properties with magnetic performance perfectly. Furthermore, the evolution characteristics of interfaces, strengthening mechanism and magnetic performance were investigated and analyzed, respectively.

\section{Materials and Methods}

Fe-Co-Ni-based maraging steel (MAS) having a tensile strength of $1086 \mathrm{MPa}$ at solution state and $2210 \mathrm{MPa}$ at peak-aged state and a commercial annealed $316 \mathrm{~L}$ austenite stainless steel were selected as the constituent materials in order to develop new LMCs. The chemical compositions (wt\%) of MAS were as follows: $0.003 \mathrm{C}, 0.0018 \mathrm{P}, 0.002$ $\mathrm{S}, 0.0014 \mathrm{O}, 0.0026 \mathrm{~N}, 17.7 \mathrm{Ni}, 15.0 \mathrm{Co}, 6.6 \mathrm{Mo}, 1.2 \mathrm{Ti}$, $0.07 \mathrm{Al}$ and $\mathrm{Fe}$ in balance. A novel fabricating method for the ultra-thin LMCs was developed as shown in Fig. 1. Firstly, two initial material sheets with a dimension of $120 \mathrm{~mm} \times 40 \mathrm{~mm} \times 2 \mathrm{~mm}$, after polishing and degreasing, were stacked together in an order of MAS/316L/.../316L/ MAS with 11 layers in total. The stacked samples were then hot-pressed in a high-vacuum atmosphere with $10^{-3}$ torr at $1200^{\circ} \mathrm{C}$ for $1 \mathrm{~h}$ under $30 \mathrm{MPa}$ to obtain an excellent bonding interface. Afterward, the stacked sample was hot-rolled on rolling mill with a rolling diameter of $130 \mathrm{~mm}$ at $1200{ }^{\circ} \mathrm{C}$ under the rolling speed of $10 \mathrm{r} / \mathrm{min}$ to the thickness of $5 \mathrm{~mm}$, and then cold rolling with a speed of $20 \mathrm{r} / \mathrm{min}$ was performed to obtain the 11-layer metal composites with a thickness of $2 \mathrm{~mm}$. Finally, asymmetrical rolling was conducted on a 4-roll asynchronous milling ( $\varphi 90 \mathrm{~mm} / 200 \mathrm{~mm} \times 200 \mathrm{~mm})$
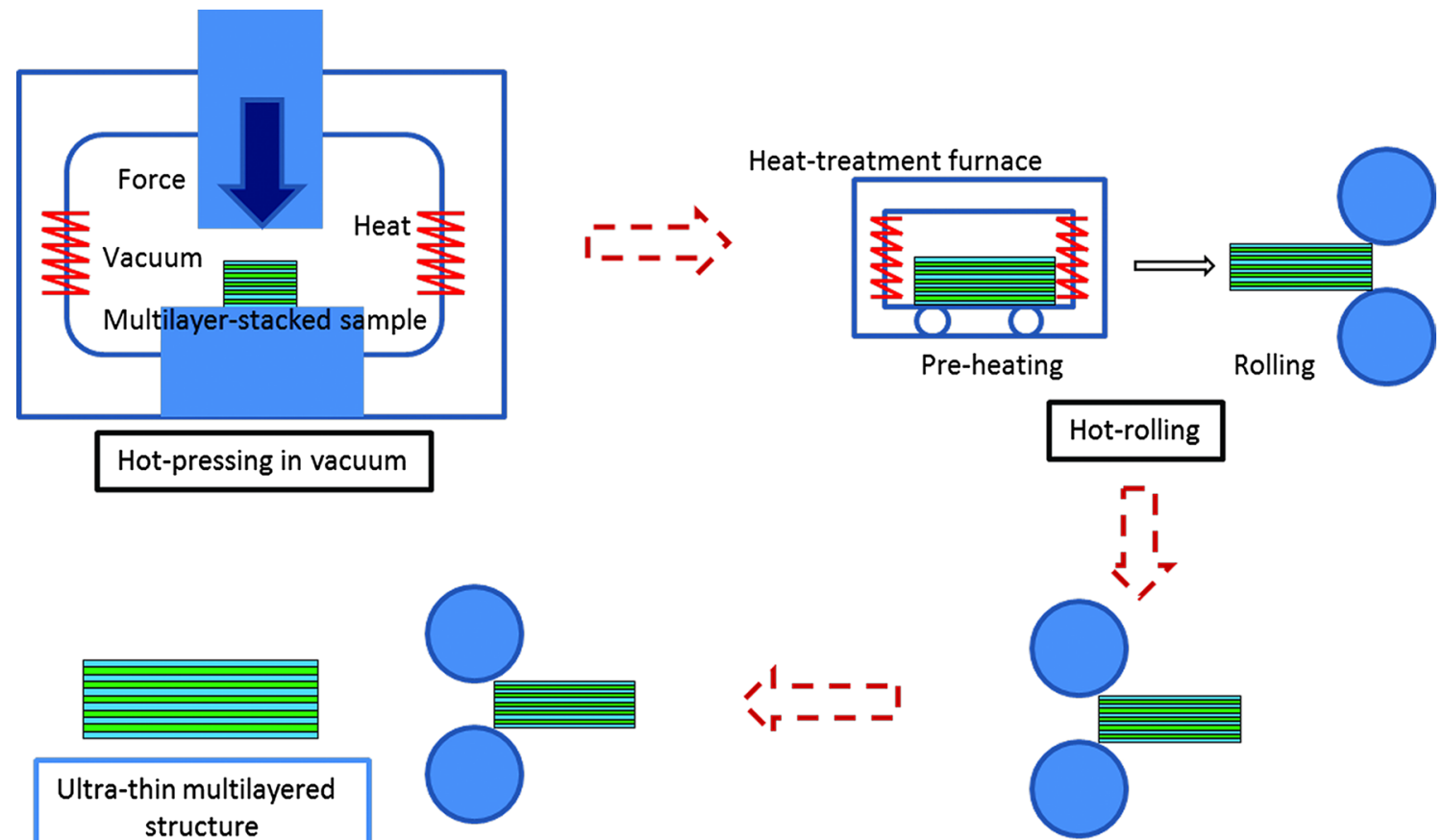

Asymmetrical-rolling

Cold-rolling

Fig. 1 Schematic diagram of the whole preparation procedure of the ultra-thin LMCs 
with an asynchronous speed ratio of 1.15 to obtain ultra-thin LMCs with various thicknesses.

The interface characteristics were observed via scanning electron microscopy (SEM, TESCAN MAIA3 $120 \mathrm{kV}$ ). The samples for micro-tensile test with $2 \mathrm{~mm}$ in width and $15 \mathrm{~mm}$ in gage length of different thicknesses were prepared, and the "load-displacement" curves were obtained by the micro-tensile test with a loading speed of $8 \mu \mathrm{m} / \mathrm{s}$. Hysteresis loops along rolling direction (RD) of ultra-thin LMCs with different thicknesses under various states were obtained using a vibrating sample magnetometer (VSM).

\section{Results and Discussion}

Figure 2 shows the evolution characteristics of interfaces after the laminated metal composites were deformed from 2 to $0.04 \mathrm{~mm}$, with about $98 \%$ reduction, via asymmetrical rolling. The interface between MAS and $316 \mathrm{~L}$ was quite clear and straight, and the thickness ratio of different layers was close to 1:1 (Fig. 2a), indicating that the deformation capacities of these two initial materials were almost similar. But when the thickness reduced to $0.22 \mathrm{~mm}$ and $0.13 \mathrm{~mm}$, respectively, the interfaces became curved at certain points as shown in marked red regions in Fig. 2b, c due to their different work-hardening capabilities. With a further increase in the deformation, as shown in Fig. 2d, the phenomenon of local neck shrinkage occurred on the $316 \mathrm{~L}$ layer, which suggested that the strength of the 316L layer was higher than that of the MAS layer. When the thickness reduced to $0.065 \mathrm{~mm}$ as shown in Fig. 2e, the local neck shrinkage became more severe and even some local positions were close to fracture. When the deformation reduction reached 98\% ( 40 $\mu \mathrm{m})$, some local neck shrinkage positions at 316L layers fractured, and the voids were filled by the relatively soft MAS layer, while a large area of wave and curl appeared on the strip surface, as shown in Fig. 2f.

Micro-tensile tests were conducted to evaluate the tensile performance of the LMCs presently studied. Figure $3 \mathrm{a}$ exhibits an obvious continuous yielding phenomenon on the "load-displacement" curves, showing that the deformation capability was decreased significantly with an increase in the reduction. When the deformation reduction was increased to $94.5 \%$ as shown in Fig. 3b, the tensile strength fluctuated within a certain range and the average value of tensile strength was about $1610 \mathrm{Mpa}$. But when the deformation reduction was increased to $96 \%$, tensile strength decreased dramatically, nearly $30 \%$, due to the internal interface disorder and the surface defects as shown in Fig. 2. In the fabrication process of ultra-thin LMCs, the strengthening effect by cold deformation was dominant. Although the initial strength of $316 \mathrm{~L}$ was lower than that of MAS, it gradually

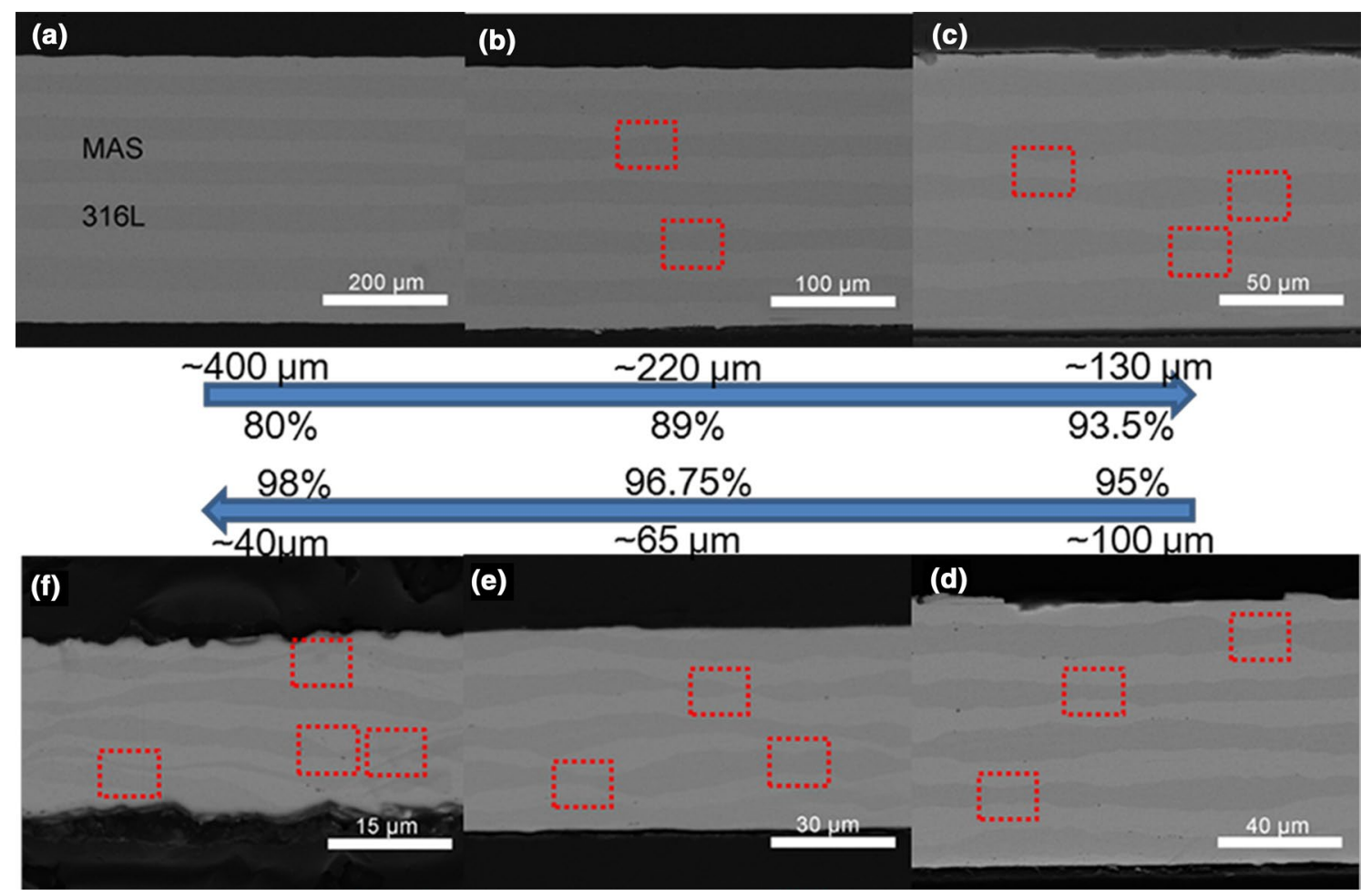

Fig. 2 Interface characteristics of LMCs with different thicknesses along rolling direction a $400 \mu \mathrm{m}, \mathbf{b} 220 \mu \mathrm{m}, \mathbf{c} 130 \mu \mathrm{m}, \mathbf{d} 100 \mu \mathrm{m}, \mathbf{e} 65 \mu \mathrm{m}, \mathbf{f}$ $40 \mu \mathrm{m}$ 

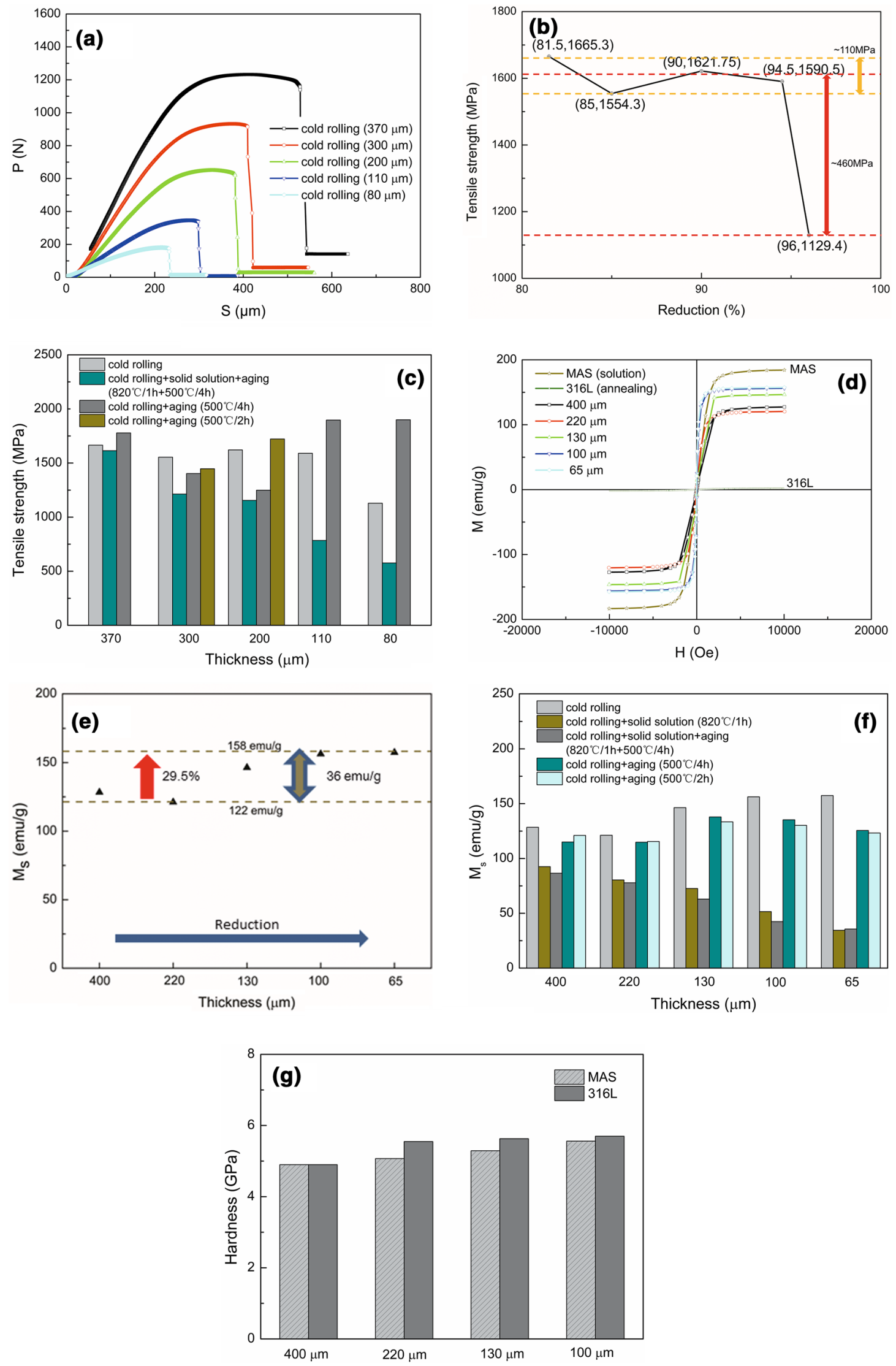
4Fig. 3 Mechanical response and magnetic performance of LMCs a "load-displacement" curves of ultra-thin LMCs with different thicknesses under cold rolling state, b "tensile strength versus reduction" curve of (a), c statistic results of tensile strength, $\mathbf{d}$ hysteresis loop of ultra-thin LMCs with different thicknesses under cold rolling state, e "saturation magnetization versus thickness" curve of (d), f statistic results of saturation magnetization, $\mathbf{g}$ average nano-hardnesses of 316L and MAS layer in LMCs with different thicknesses

became comparable to MAS with the increase in the deformation owing to its higher work-hardening ability compared to MAS. Coupled with the coordination role of strong interfaces, the ultra-thin LMCs exhibited extremely high strength and great deformation capability. But with a further increase in the deformation as shown in Fig. 3g, the hardness or strength of $316 \mathrm{~L}$ was gradually higher than that of MAS, and when the neck shrinkage occurred on $316 \mathrm{~L}$, the gaps left by the neck shrinkage were filled by relatively soft MAS. But the interfaces were no longer able to coordinate the deformation for extensively high strength of these two materials. During the tensile loading process, the disordered interfaces could not transmit the load and were easy to cause the stress concentration at local neck shrinkage positions, resulting in the formation of micro-cracks, which led to the decreases in both strength and plasticity. Precipitation hardening is the main strengthening mechanism for MAS. To maximize the strength of the ultra-thin LMCs, their mechanical response with different states was investigated. It can be seen from Fig. $3 c$ that after solid solution and aging treatment, the loading capacity and tensile strength were decreased significantly mainly because the hardening effect of precipitation in MAS could not offset the softening effect caused by dynamic recovery and recrystallization of MAS and 316L layers after solid solution at high temperature. But the tensile strength could be further enhanced if the heat treatment process of direct aging without solid solution after cold rolling was adopted, which could make full use of the precipitation hardening and work strengthening mechanism. Obviously, the ultra-thin LMCs exhibited super-high strength and their mechanical performance could be regulated by adjusting the heat treatment process to meet the requirements of various application challenges.

The ultra-thin LMCs not only exhibited excellent mechanical properties, but also showed unique magnetic performance. Figure 3d shows that ultra-thin LMCs with various thicknesses of cold rolling state presented quite high magnetic permeability and low coercive force $(<28 \mathrm{Oe})$. Meanwhile, with an increase in the reduction, saturation magnetization $\left(M_{\mathrm{s}}\right)$ increased significantly by about $29.5 \%$ from 122 to $158 \mathrm{emu} / \mathrm{g}$, which is much higher than those obtained according to the mixed rule $(98 \mathrm{emu} / \mathrm{g})$ as shown in Fig. 3e. The huge increase in $M_{\mathrm{s}}$ could be attributed to the formation of strain-induced martensite in the 316L layer during the large reduction process [20]. The obtained maximum
$M_{\mathrm{s}}$ value is comparable to that of maraging steel reported by Pardal et al. [19] and Tavares et al. [21]. Furthermore, the magnetic properties of ultra-thin LMCs under different heat treatment states were also examined as depicted in Fig. 3f. The LMCs of different thicknesses exhibited almost similar characteristics. The saturation magnetization considerably changed with different heat treatment processes. Due to the transformation of strain-induced martensite into austenite in the 316L layer after solid solution at high temperature [20], a sharp drop in saturation magnetization occurred compared to a slight decrease with direct aging after cold deformation. In addition, the formation of a small number of non-magnetic nanoscaled precipitation and reverted austenite in the MAS layer slightly decreased the $M_{\mathrm{s}}$ after aging $[19,21]$.

\section{Conclusion}

In summary, $\mathrm{Fe}-\mathrm{Co}-\mathrm{Ni}$-based maraging steel and 316L austenite stainless steel sheets were well utilized to successfully fabricate the ultra-thin LMCs with a thickness of 400 to $40 \mu \mathrm{m}$. These LMCs with various thicknesses exhibited ultra-high strength $(\sim 1610 \mathrm{MPa})$ and excellent soft magnetic properties with a very high saturation magnetization of $122-158 \mathrm{emu} / \mathrm{g}$. In addition, post-heat treatment could offer an effective way to control the mechanical performance and magnetic characteristics of the ultra-thin LMCs. And more detailed work like interface bonding characteristics and microstructure evolution needs to be conducted to further investigate the relationship among microstructure characteristics, mechanical properties and magnetic performance.

Acknowledgements This work was sponsored by the Youth Innovation Promotion Association of Chinese Academy of Sciences (No. 2017233), the National Natural Science Foundation of China (No. 51472249), the Innovation Project of Institute of Metal Research (No. 2015-ZD04) and the National Natural Science Foundation of China Research Fund for International Young Scientists (No. 51750110515).

\section{References}

[1] B.L. Smith, T.E. Schäffer, M. Viani, J.B. Thompson, N.A. Frederick, J. Kindt, Nature 399, 761 (1999)

[2] Z. Tang, N.A. Kotov, S. Magonov, B. Ozturk, Nat. Mater. 2, 413 (2003)

[3] R.O. Ritchie, Nat. Mater. 10, 817 (2011)

[4] O. Bouaziz, J.P. Masse, G. Petitgand, M.X. Huang, Adv. Eng. Mater. 18, 56 (2016)

[5] J. Yanagimoto, T. Oya, S. Kawanishi, N. Tiesler, T. Koseki, CIRP Ann. Manuf. Technol. 59, 287 (2010)

[6] F. Daneshvar, M. Reihanian, Kh Gheisari, Mater. Sci. Eng. B 206, 45 (2016)

[7] L.X. Xu, H.B. Wu, X.T. Wang, Acta Metall. Sin. (Engl. Lett.) 31, 389 (2018)

[8] J. Moon, S.J. Park, J.H. Jang, T.H. Lee, C.H. Lee, H.U. Hong, H.N. Han, J. Lee, B.H. Lee, C. Lee, Acta Mater. 147, 226 (2018) 
[9] B.X. Liu, L.J. Huang, L. Geng, B. Wang, X.P. Cui, C. Liu, G.S. Wang, Mater. Sci. Eng., A 583, 182 (2013)

[10] M. Naseri, M. Reihanian, E. Borhani, J. Manuf. Process. 24, 125 (2016)

[11] K.D. Leedy, J.F. Stubbins, Mater. Sci. Eng. A 297, 10 (2001)

[12] S. Roy, B.R. Nataraj, S. Suwas, S. Kumar, K. Chattopadhyay, Mater. Des. 529, 36 (2012)

[13] M. Naseri, M. Reihanian, E. Borhani, J. Manuf. Process. 125, 24 (2016)

[14] A. Mozaffari, M. Hosseini, H.D. Manesh, J. Alloys Compd. 9938, $509(2011)$

[15] H.L. Yu, C. Lu, A.K. Tieu, H.J. Li, A. Godbole, C. Kong, Mater. Sci. Eng. A 195, 660 (2016)
[16] S.C. Jha, R.G. Delagi, J.A. Forster, P.D. Krotz, Metall. Trans. A 15, 24 (1993)

[17] X.P. Zhang, T.H. Yang, S. Castagne, J.T. Wang, Mater. Sci. Eng. A 1954, 528 (2011)

[18] K.D. Leedy, J.F. Stubbins, Mater. Sci. Eng. A 10, 297 (2001)

[19] J.M. Pardal, S.S.M. Tavares, M.P. Cindra Fonseca, M.R. da Silva, J.M. Neto, H.F.G. Abreu, J. Mater. Sci. 42, 2276 (2007)

[20] S. Tanhaei, K. Gheisari, S.R. Alavi Zaree, Int. J. Mine. Metall. Mater. 25, 42 (2018)

[21] S.S.M. Tavares, M.R. da Silva, J.M. Neto, J.M. Pardal, M.P. Cindra Fonseca, H.F.G. Abreu, J. Alloys Compd. 373, 304 (2004) 